\title{
Hacia la representación de una ciudad épico-queer: Diego Ramírez Gajardo'
}

\section{Towards the Representation of an Epic-Queer City: Diego Ramírez Gajardo}

\author{
Francisco Simón \\ Pontificia Universidad Católica de Chile / Becario CONICYT \\ fjsimon@uc.cl
}

Resumen • El siguiente artículo pretende instalar la obra El baile de los niños, del poeta chileno Diego Ramírez Gajardo, en el marco de una enunciación homosexual antecedida al menos desde la década de los setenta. De esta forma, pensaré dos registros vocales que, fusionados, operarán una metáfora donde el baile revelará las imposturas de una cultura nacional emplazada en el espacio urbano. El primer registro se refiere a la relación intertextual con el Canto general de Pablo Neruda, mientras el segundo simboliza la constitución travestida de la voz poética. Luego, la conjugación de ambos discursos conformará una épica queer, es decir, un tipo de intersección discursiva marcada por un flujo bidireccional entre la sublimación y la degradación del mundo representado, una apropiación de la historia nacional por parte de la disidencia sexual.

Palabras clave: Baile, Queer, Ciudad, Simulacro, Historia

Abstract - The following article aims to install the work El baile de los niños, by Chilean poet Diego Ramírez Gajardo, into the context of a homosexual enunciation preceded at least since the seventies. Thus, I will think about two vocal registers that, fused, will develop a metaphor where dance will reveal the impostures of a national culture placed in the urban space. The first register refers to the intertextual relation with Pablo Neruda's Canto General; the second, symbolizes the transvestite constitution of the poetic voice. Then, the conjugation of both discourses will shape a queer epic, that is, a type of discursive intersection marked by a bidirectional flow between the sublimation and the degradation of the represented world; an appropriation of the national history by the sexual dissidence.

Keywords: Dance, Queer, City, Simulacrum, History

Este artículo se inscribe dentro del proyecto Fondecyt $\mathrm{N}^{\circ} 1085255$, «Representaciones de la ciudad en la poesía posgolpe», cuya investigadora responsable es Magda Sepúlveda Eriz. 


\section{ah, querida, aunque estos chicos tecno producidos para un triste futuro, bailen a Madonna aunque pinten su cabellera india de rubio platinado y beban hasta caer muertos, son los hijos del tirano de Chile.}

Nada, Malú Urriola

El 8 de enero del 2005 se celebró por primera vez en el centro de Santiago el evento masivo Love Parade, que congregó cerca de cien mil personas. Al año siguiente, la fiesta se desarrolló nuevamente, duplicando la cantidad de asistentes. Tales celebraciones pretendían pregonar la reterritorialización de la plaza pública por medio del baile: el parade instalaba un carnaval cuyo signo amoroso construía una población danzante que se había tomado las calles. Mientras tanto, la música electrónica aplazaba a la pareja heterosexual, visibilizando en el escenario urbano aquellos personajes que hasta ahora sobraban: travestis, lesbianas, homosexuales, todos juntos, danzando en el seno de la ciudad. Luego, la experiencia de esa reunión elaboraba al cuerpo como plataforma de un espectáculo utópico: la fiesta diurna y veraniega recreaba un sueño de equivalencia democrática entre sujetos in love, enamorados. No podía ser de otra manera, las fiestas se denominaron «Sal a la calle y baila» (2005) y «El baile es de todos» (2006).

Por su parte, simultáneamente al desarrollo de esas celebraciones, hacia fines del 2005 se publicó la obra El baile de los niños, de Diego Ramírez Gajardo. Así, y sobre la base de un significante recurrente entre ambas expresiones culturales, me parece que existe un vínculo que en el imaginario contemporáneo ha constituido al baile como un modo de aproximación a la realidad, cuya particularidad se emplaza en el cuerpo, es decir, en aquella entidad que "obedece las fronteras de sentido que la discursividad social prescribe como normalidad o bien se estrella contra ellas» (Richard, 78). Justamente, pienso que tanto la experiencia masiva del Love Parade como el poemario de Ramírez recrean una apuesta por lo corporal, pues en ambos casos se ha comprendido que por medio de esta materialidad es posible actuar un proyecto, una resistencia en contra de un allá verbalmente discursivo e institucional.

En ese sentido, quisiera precisar cómo Ramírez ha sido inscrito dentro de la promoción de poetas del 2000 o novísimos, junto a Héctor Hernández Montecinos, Paula Ilabaca, Felipe Ruiz, Gladys González y Pablo Paredes, entre otros. Acerca de la poética de dichos autores, el mismo Hernández ha planteado que esas voces «escriben desde la desobediencia de sus quehaceres hogareños, estudiantiles, familiares y hasta juveniles. $\mathrm{Y}$ a pesar de todo siguen con la palabra como resistencia e intervención» (s/n). Por su parte, también Ruiz agrega que «la poesía novísima se planteó desde la ambigüedad sexual, desde la promiscuidad y la belleza (a veces demencial) de la marginación como una última frontera, como una guerra sin cuartel contra las promesas rotas del proyecto concertacionista» («Poetas en el acto», 12). A esos poetas les interesará plasmar su letra en el campo, gestionar su ingreso al canon y, sobre todo, hablar, cristalizar su presencia 
por medio de una vociferación permanente ${ }^{2}$, que les permita textualizar sus cuestionamientos con respecto al Chile del siglo veintiuno.

Para el caso de Ramírez, me importará pensar, entonces, cómo la «desobediencia» y la «ambigüedad» novísima adquirirán relevancia política al constituirse en un cuerpo indócil que, por medio de una plataforma como el baile, dirá el desmembramiento de la cultura nacional: «En este paraíso descubierto / la gente se dedica a bailar / la política del baile es para olvidarse de todo lo que se hizo antes de conocer a cada / huacho / moquiento / solito / feliz» (El baile, 27). Así, y como bien afirma Malú Urriola, la voz poética aquí presenta "Una tensión en sus versos que cruza y anuda traumas de revoluciones frustradas, problemáticas de género, contragénero, y del poder que se ejerce sobre los cuerpos» ( $\mathrm{s} / \mathrm{n})$. El mundo de Ramírez se enunciará a partir de una cosmología que ubica la irradiación discursiva en los márgenes de la cultura, de manera que se pretenderá decir una versión alternativa de nuestra historia.

De acuerdo con lo anterior, si previamente dije que el Love Parade instalaba una utopía amorosa en la urbe, el baile en Ramírez será atraído desde un lugar inverso: los cuerpos aquí transitan por las calles, oscurecidos, mientras en las discos se exhiben heridas sintomáticas: «Entender que tengo tantas cicatrices de deseos y miedo que ya no puedo tanto poder escribir» (El baile, 75). Así, me sumo a la apreciación realizada por Patricia Espinosa, quien ha planteado cómo dicha obra «ejecuta de modo impecable una escritura en donde la infancia huérfana y el territorio del deseo resultan bellamente infectos y aterradores» $(\mathrm{s} / \mathrm{n})$. En efecto, los individuos aquí son andróginos, se hallan perforados, «sobre los pelos varios, punk, lisos, rubios, colorcito, chasquillas, mechitas largas / Escondida la miradita, la niña como niño, / los hombrecitos de rosado y con polerita de la hermana» (Ramírez, El baile, 11). El hablante nombrará un baile que ya no es masivo, sino localizado; no diurno, sino noctívago; y no abierto, sino hermético. Así, la ciudad, «como marco y contexto de significados para un cuerpo sexuado» (Guerra, 290) ${ }^{3}$, será intervenida por el proyecto de Ramírez, quien difuminará cualquier utopía, en cuanto concebirá una urbe des-realizada y plastificada, vuelta un pastiche, es decir, una "parodia vacía» ${ }^{4}$ (Jameson, 45$)$, un simulacro pop de sujetos cuyo goce se halla en la superficie de las pantallas visuales que tapizan los muros de la discoteca.

2 En efecto, estos autores han entendido que su participación en el campo cultural chileno deberá negociarse por cada medio disponible: a través de la participación en talleres (véase Balmaceda 1215 o Santa Rosa 57); a través de concursos por becas y premios (Fundación Pablo Neruda, Fundación Mustakis o Consejo Nacional del Libro y la Lectura); o por medio de la organización de encuentros, como Poquita Fe, en 2004. Asimismo, accederán a la elaboración de autoediciones ("Contrabando del bando en contra», o «Moda y pueblo», dirigida por Ramírez); y utilizarán recursos virtuales, como blogs, que varios de ellos poseen, al tiempo que realizarán constantes interlecturas: se leerán, presentarán y reseñarán.

3 Lucía Guerra también ha afirmado cómo «La experiencia de ese Yo/Cuerpo Sexuado que transita por el espacio urbano está marcada por la familiarización o desfamiliarización creadas por los privilegios o discriminaciones del orden genérico prevalente» (289). En ese sentido, me interesa pensar la ciudad desde los signos genéricos que la construyen, de modo que un sujeto no pueda sino reproducir y/o transgredir la simbología cartográfica que a su cuerpo le ha sido asignada, y donde quien actúa una sexualidad alternativa de inmediato se convierte en una amenaza para la construcción heteronormativa de la ciudad.

4 Jameson define la cultura posmoderna como pastiche, en tanto una sustitución cultural de la historia por un historicismo izado sobre las ruinas de la realidad, sobre su simulacro, es decir, la "copia idéntica del que jamás ha existido el original» (45). De esta forma, "estamos condenados a perseguir la Historia mediante nuestras propias imágenes pop y mediante los simulacros de esa historia que, por su parte, queda absolutamente fuera de nuestro alcance» (60). 
De esa manera, el baile acusará a aquellos cuerpos que han instalado sobre sí los timbres de un marketing mnémico nacional que los ha convertido en materia de desperdicio patrimonial: «La marquita de sus grupitos / Y las cruces y sus fobias tatuadas pendejitas sobre el bolsito escolar» (El baile..., 9). Según Ramírez, son sujetos aprehendidos por la histeria del consumo, aquellos que sólo quieren parecer, que escriben en sus cuerpos una historia de la que no tienen recuerdo, en cuanto se trata de «identidades que sensibilizan simbólicamente con el negro, la negrura de esta noche chilena entregada a la pulsión tanática de su historia actual» (Ruiz, «Dulce perversión infantil», 2006). Huachos, bastardos, indios y rotitos pueblan la disco, mientras simulan la coreografía de fantasías reidentitarias: "Como identificación mi niñito perdido que se reconoce así, todo parchado de sexo, todo cruzado por metálicas formas, para que no lo dejen solito cuando se derrite con el dance alternativo de su pista bailable» (Ramírez, El baile, 10).

De esa manera, se ha producido un desplazamiento que coloca la discoteca allí donde antes existía el signo de la nación, pues, aquella «ocupa el lugar de la plaza pública, ahí se produce el mirar sin conocer, el peligro, el choque, pero también la integración cultural» (Sepúlveda, 2) ${ }^{5}$. Desde aquí, la función baile, al intervenir una mirada sobre la urbe, reescribirá, en clave desgastada, una versión personal de la historia nacional. El imaginario poético aquí se dirigirá hacia la representación de las subculturas juveniles, las subsexualidades que se hallan desaparecidas a la luz del día, por las calles de la ciudad.

A propósito de lo dicho con anterioridad, quisiera leer El baile de los niños como una enunciación enmarcada bajo un discurso homosexual cuya retórica se halla antecedida al menos desde la década de los setenta. En ese sentido, me parece posible pensar el proyecto de Ramírez en términos de una radicalidad representacional, por cuanto su textualidad no sería meramente gay, sino que sobre todo queer, en cuanto aquí ha sido comprendido cómo «la heterosexualidad [...] es un sistema altamente inestable [...] dependiente de la exclusión de la homosexualidad para su propia identidad ${ }^{6}$ (Stein y Plummer, 135). Así, esta enunciación, a diferencia de otros discursos homosexuales, no es sólo reivindicativa, sino también subversiva: no reclama igualdad de derechos, sino que su contraviolencia pretende revelar la performance heterosexual, los procesos de elaboración que la construyen; exhibir la existencia de otros cuerpos sexuados, para tensionar los signos heteronormativos.

De esa forma, pensaré dos registros vocales que, fusionados, operarán la metáfora poética. El primero trata sobre la relación intertextual existente con el Canto general de Pablo Neruda, mientras el segundo tiene que ver con la constitución travestida de la voz hablante. Luego, la conjugación de ambos registros constituirá lo que he denominado una épica queer, caracterizada como un tipo de intersección discursiva marcada por un flujo bidireccional entre la sublimación y la degradación del mundo representado; una apropiación de la cultura institucional por parte de la disidencia sexual.

5 Destaco aquí la reflexión suscitada por Magda Sepúlveda, quien ha estudiado la isotopía de la disco en la poesía de Diego Ramírez, Héctor Hernández y Pablo Paredes. De acuerdo con su lectura, este espacio opera como lugar de encuentro e identificación «con comunidades que se reconocen fuera de la nación, apostando a un país posChile, conformado por comunidades étnicas, gay, travestis, bisexuales, y tribus andróginas, y un desborde del significante que trabajan fuera de la economía burguesa [...] en un ritmo que hace convivir la cultura letrada [...] con la industria mass mediática de audiencia popular» (2).

6 En el original, «Heterosexuality [...] is a highly unstable system, [...] dependent upon the exclusion of homosexuality for its very identity» (Stein y Plummer, 135). 


\section{CANTO PARTICULAR, ESCRITURA GENERAL: POR UNA INTERVENCIÓN ÉPICA}

En principio, cuando se trata de la voz nerudiana, ésta debe ser tratada desde la mirada de lo épico e histórico que enuncia, sellada en Canto general desde su mismo título: lo que dicha obra tiene de general se relaciona con la posición de un sujeto aproximado a una omnisciencia histórica, mientras el canto posibilita un eco homérico y oral. De esa manera, el hablante insistirá una y otra vez sobre su acto representacional: «Yo estoy aquí para contar la historia» (Neruda, 7), o bien, "Yo vengo a hablar por vuestra boca muerta» (35). Él viene aquí a hablar por otros, a posicionarse como apoderado de aquellos que somos los indígenas y mestizos americanos, aquellos cuya historia se organiza en función de una conquista, una colonización, un velo que ha opacado cualquier posibilidad de autorreconocimiento simbólico, pues seríamos sólo la sobra, todo lo que no es el individuo europeo.

Al mismo tiempo, si la voz nerudiana ha accedido a la posición del canto es porque ha transitado por la ciudad mundana: «Del aire al aire, como una red vacía, / iba yo entre las calles y la atmósfera» (Neruda, 23), preguntándose por «lo indestructible, lo imperecedero, la vida» (25). De esa forma, el sujeto quiere reivindicar y redibujar una historia en clave panorámica, mientras su voz ostenta un saber que, por consiguiente, le permite cantar, representar y salvar el abismo de una identidad americana. Se trata de una voz heroica, arquetípica, y sobre todo (re)fundacional, o así nos ha sido presentada. En efecto, no quisiera omitir el hecho de que el sujeto poético en Canto General también enuncia que «hoy que los pistoleros se pasean / con la «cultura occidental en brazos, con las manos que matan en España / y las horcas que oscilan en Atenas / y la deshonra que gobierna a Chile» (Neruda, 391). Al fin, un canto cuyas coordenadas ideológicas el archivo nacional ha anulado, desechando la resistencia cultural que ese hablante también experimentaba, como Ramírez, hacia 1950: «Este libro termina aquí. Ha nacido / de la ira como una brasa, como los territorios / de bosques incendiados, y deseo / que continúe como un árbol rojo / propagando su clara quemadura» (Neruda, 392). Me parece que aquel incendio simbólico fue extinguido, mientras nos han enseñado las cenizas, las partículas inofensivas, incapaces de generar reflexión crítica, sino más bien sólo una observación grandilocuente libre de su carga política.

En ese sentido, es pertinente pensar la voz nerudiana en cuanto al mito de lectura que el canon ha elaborado sobre ella: las interpretaciones musicales de Los Jaivas, la ostentación masculina del Nobel o su partidismo político, han convertido a Neruda en el poeta de exportación de la poesía nacional. De esa forma, también el poeta es la representación de una virilidad bien chilena, donde el Neruda-pícaro, el Neruda-galán o el Neruda-romántico son todas imágenes repetitivas cuando se imagina al autor de los Veinte poemas de amor... Así, la celebración de su centenario en el 2004 legitimará su repercusión histórica en las letras patrimoniales, convertido ya en lectura gubernamental para la enseñanza escolar; representante oficial del ascenso nacional a las cumbres de la Literatura Moderna.

De esa manera, la promoción novísima también celebró la fiesta conmemorativa a Neruda, esta vez reescribiendo, precisamente, su Canto General. Titulado como Desencanto personal, en el 2004 el poeta Javier Bello seleccionó una serie de textos de distintos autores noveles que, en el marco de aquel desencanto, señalan tanto una desilusión con 
respecto a la textualidad épica de Neruda, como un desarme, una desarticulación de aquel discurso ${ }^{7}$. Destaco la propuesta poética de Felipe Ruiz, quien ingresará un código pop/vulgar para decir la degradación del discurso nacional nerudiano: «come to burn with me, brother / give me your hand, give me your hand // ojitos de gata alquinta / ojitos hediondos de gatito / muerto / seco // papada de ballena nerudiana / podrida pescá seca» («Bajezas de Machu Pichu», 129). Así, el centenario de Neruda devendrá asistencia a un velorio donde el cuerpo se halla exhumado; se ha abierto la tumba, para encontrarse con una palabra poética que hiede, que se halla descompuesta, mientras el canon nación es ofrecido como ofrenda sacrílega.

Ramírez luego polemizará la mitificación nerudiana, su investidura nacionalista, al aseverar cómo su propia escritura «nunca bailó ese gesto de la patria orgullosa de su falo» (El baile, 75), a diferencia del canto generado por el Nobel. Así, el hablante se percatará de lo extemporáneo del discurso de Neruda, y desde ahí actualizará una anulación del canto como acto simbólico, al tiempo que nombrará la imposibilidad de constituir una identidad nacional, mientras la palabra poética "pierde su tranquilidad y seguridad para llegar a ser turbulenta, irresoluble internamente y ambivalente» (Bajtín, 277) ${ }^{8}$. En El baile de los niños lo general será desplazado por un particular, mientras la conciencia escritural desaloja al canto: «Si yo bailo cuando escribo y escribo cuando bailo / no puedo hacerlo de otra forma» (39), afirmará la voz poética, insinuando, además, cómo su escritura será correlato del cuerpo, el significante por pervertir y transformar.

En ese sentido, la voz de Ramírez desarmará cualquier textualidad épica, al desarticular el estatuto de una historia americana y nacional, en tanto el mundo de este sujeto no aparece, ni puede aparecer, integrado a una identidad continental. De esa manera, la primera sección del poemario, titulada el «Baile general de los niños», repetirá el número de los distintos cantos de la obra de Neruda, aunque deformando los signos que la construyen: en vez de «I. La lámpara en la tierra», Ramírez escribirá «I. Lucecitas Candy». Ambos enunciados se refieren a un mismo sema luminoso, pero si Neruda piensa en una metáfora telúrica, el novísimo atraerá una imagen plastificada: esas luces, las del baile, son fluorescentes, desechables. Asimismo, si el sujeto nerudiano afirmaba que «No hay nadie. Escucha el árbol, / escucha el árbol araucano» (22), la nueva versión dirá cómo «No hay nadie esta noche y sin embargo sólo les escribo a estos niños que se saben resignados y felices en el baile general de lo que queda de país» (Ramírez, El baile, 23). Desde aquí se manifiesta cómo la realidad representada por Ramírez problematiza la existencia de un discurso nacional, en tanto el acento se halla puesto sobre la posición de una serie de sujetos vueltos sobra de la patria: «Las niñas que yo conozco no aparecen en la historia más heroica del país / Porque ellas dicen que se les olvidan las cosas que han hecho en la vida» (El baile, 31). Así, el saber del hablante novísimo privilegiará la representación de quienes han carecido de participación cultural, de voz ciudadana.

\footnotetext{
La compilación incluye textos de Víctor López, Simón Villalobos, Rodrigo Olavarría, Marcela Saldaño, Manuel Llancao, Héctor Hernández, Felipe Ruiz, Fanny Campos, Eduardo Barahona y Diego Ramírez, quien editó «Baile General de los niños», después convertido en la primera parte de El baile de los niños. Atraigo la noción de polémica explícita o abierta, propuesta como categoría intertextual según Bajtín, cuando la tensión discursiva que un texto mantiene con otro "va dirigida simplemente hacia la palabra ajena y refutada como hacia su objeto» (274).
} 


\section{EL BAILE Y SU CUERPO HOMOSEXUAL: POR UNA INTERSECCIÓN QUEER}

El segundo registro que conforma la voz en Ramírez es un discurso que, al contrario del nerudiano, es un habla deslegitimada: históricamente marginal, el poeta retoma el discurso homosexual en clave travesti, degradado y popular. En efecto, Víctor Hugo Robles dice que la primera manifestación homosexual en Chile fue realizada por un conjunto de travestis en abril de 1973, de modo que «un grupo, de aproximadamente 25 homosexuales, de estrato popular, protestaron en la Plaza de Armas de la capital» (15). Subrayo, entonces, cómo esta enunciación queer aparece marcada ya por el signo de la marginalidad social. Así, ese será el puntapié para una serie de protestas y performances que heredarán dicha disposición travestida para politizar y visibilizar el problema homosexual en nuestro país.

Por su parte, y durante los ochenta, los escritores Pedro Lemebel y Francisco Casas se reunirán para conformar el dúo Las Yeguas del Apocalipsis, instalando «en el imaginario colectivo la transgresora figura del travesti pobre y prostibular» (Robles, 29). Con ellos, y por medio de distintas acciones de arte, fue recuperado el signo de aquellos individuos que protestaron durante la década de los setenta, configurándose un encadenamiento representacional que insistía en una transgresión cultural efectuada desde la transfiguración entre lo masculino y lo femenino ${ }^{9}$. Así, véase la intervención que el dúo realizó el 12 de octubre de 1989, en los Salones de la Comisión de Derechos Humanos, donde ambos bailaron un pie de cueca sobre un mapa de América Latina dibujado sobre el piso que, a su vez, se hallaba cubierto de trozos de vidrio. Según Lemebel, esa «fue una de las acciones más políticas, porque ahí estaba nuestra huella: estaba la sangre y el baile. Ahí estaba todo, el contagio del SIDA, los desaparecidos, dos hombres y también estaba el doblaje de dos mujeres solas» (cit. en Robles, 28). Nótese el baile como dispositivo simbólico en esta representación, signo angular en el desarrollo de las próximas intervenciones gay en espacios públicos ${ }^{10}$.

También durante los noventa se repetirá la instalación queer, ahora encarnada por la presencia del Che de los Gays (alter ego del mismo V. H. Robles), quien intentó «reinventar metafóricamente la utopía libertaria de la izquierda latinoamericana, pero encarnada en personajes contemporáneos, desvalidos y estigmatizados, entre ellos, las minorías sexuales» (Robles, 9). En ese sentido, quisiera destacar la representación efectuada el 21 de noviembre de 1997, en la inauguración de la $17^{\mathrm{a}}$ Feria Internacional del Libro de Santiago, donde el Che, con sus labios maquillados y una boina, apareció en el escenario bailando «una desenfrenada cueca al ritmo de la canción nacional, mientras gritaba "iJuicio a Pinochet, juicio a Pinochet, por los desaparecidos, juicio a Pinochet!» (Robles, 107). Nuevamente, y en consonancia con la performance de Las Yeguas del Apocalipsis, la cueca, y de manera general el baile, se vuelve significante recurrente para visibilizar la marginalidad cultural de quienes experimentan una sexualidad divergente.

$9 \quad$ Este recurso transformista sobre la palabra masculina tiene otros antecedentes heredados de la poesía producida durante los años ochenta: Raúl Zurita en Purgatorio (1979), Diego Maquieira en La Tirana (1983), o Sergio Parrra en La manoseada (1987) también problematizan la virilidad patriótica a través del travestimo poético, aunque me parece que están mucho más concentrados en incomodar al discurso dictatorial, que en reivindicar una sensibilidad homosexual.

10 Es el caso de las gay parades organizadas por el Movimiento de Integración y Liberación Homosexual (MOVILH), cuyas fiestas desarrolladas en el espacio urbano localizan al baile como significante de la experiencia de integración y liberación. Desafortunadamente, me parece, se trata de celebraciones sólo carnavalescas, en cuanto son autorizadas y fiscalizadas por la institucionalidad municipal, al tiempo que la visibilidad homosexual es revelada por apenas una jornada: premio de consuelo para reprimir cotidianamente. 
De acuerdo con lo anterior, cada uno de los momentos mencionados comparte la experiencia de una lucha representada en la performance corporal: labios pintados y pelo en pecho, la manifestación travesti construye cuerpos limítrofes capaces de degradar el saber heterosexual. Contra la Dictadura o la Transición, devienen amenazas sobre el imaginario cultural de la patria ${ }^{11}$. Son cuerpos que, travestidos, también son ominosos: atraen una fantasmagoría terrorífica «que se remonta a lo consabido de antiguo, a lo familiar desde hace largo tiempo" (Freud, 220); nos señalan el retorno peligroso de los sujetos abyectos, excluidos y fronterizos, que moldean la construcción de la nación.

Me parece que en Ramírez ese tipo de discursividad queer será cultivada y yuxtapuesta como signo de resistencia sobre la enunciación nerudiana, en cuanto a la composición travestida de la voz poética: "Yo estoy cansado, vieja demacrada y frágil ante toda la competencia de esta modernidad» (El baile, 11); «vamos a ser todas chicas plásticas de esta galería moderna» (36); «nunca nadie / así de solito / y enfermito / para mirarlos / todo baboso / a ustedes» (27). Todas ellas son intervenciones a modo de autorretrato que delinean el cuerpo y la escritura de quien enuncia: masculino-femenino, travesti; degradado, enferma, solitario, calificativos de esa voz que se localiza como escribidor de una resistencia activa contra la historia: «Si no le gusta, yo soy así, le frivolizo el sistema fundacional, le desordeno el gesto discursivo, la única estética posible, la única mirada general desde lo particular del baile, desde la decadencia maltratada de mis niñitos de vanguardia importada que no saben leer, pero se lo hacen rico cuando se les acaba la noche» (El baile, 39).

Si Las Yeguas del Apocalipsis y el Che de los Gays bailaron una cueca para decir la exclusión del habla homosexual ante el resto del país, Ramírez por su parte adoptará también el baile, desechando la relevancia simbólica de la cueca como estandarte nacional, y atrayendo la música pop que la irrupción del nuevo capitalismo masificó sobre la población. Su mirada se concentrará en una reflexión sobre los espacios subculturales que las políticas públicas construyeron, a modo de «donación» democrática, para quienes no debían ser vistos a la luz del día, aunque aún debieran pagar sus impuestos.

\section{SIMULACRO URBANO Y CUERPOS PLASTIFICADOS: UN CRIMINAL ANDA SUELTO}

De acuerdo con Víctor Hugo Robles, quisiera plantear la siguiente reflexión en torno a la aparición de los primeros lugares de baile homosexual en nuestra capital:

[...] la ideología de libre mercado permitió el surgimiento de las primeras discotecas gays y de bares topless en la capital, institucionalizando con esto último el comercio sexual femenino. Sin embargo, aquello no significó un cambio rotundo en la postura oficial al respecto del tema, sólo el reconocimiento tácito de un mercado económico unido a la posibilidad cierta de una vida gay nocturna, destacando aquí la disco Fausto de Providencia (20-1).

${ }_{11}$ Pienso aquí en una película alemana estrenada el 2004 y dirigida por Bruce LaBruce, The Rasperry Reich (2004). En ella, un grupo de terroristas reclama una revolución contra el imperialismo capitalista marcada por el signo subversivo que implica la homosexualidad, de modo que una de las consignas impulsadas por Gudrun, la líder, es «La heterosexualidad es el opio del pueblo». 
Según lo anterior, me parece que una mirada sobre lo urbano de la disco debe ser efectuada necesariamente sobre la base de la implicación económica y política que tiene. En efecto, desde aquí la marginalidad del sujeto queer y sus espacios sólo puede ser pensada como una construcción deliberada. Al fin, la habilitación de lugares públicos para la reunión de homosexuales durante la Dictadura tiene que ver con la aplicación del sistema de neocapitales, de modo que opera una instrucción por visibilizar al gay de una manera económicamente sustentable: para la opinión pública ésta es la otredad perversa, mientras para el queer es un derecho ganado.

Sin embargo, y sumándome a la argumentación de Leo Bersani, agregaría que esa permisión institucional del espacio gay, aunque nocturno, funciona también como dispositivo de control: «la visibilidad es una precondición de la vigilancia, la intervención disciplinaria y, en el límite, la limpieza de género» (25), de manera que una vez que existe mirada, existe una alerta, mientras el discurso atrae nuevos objetos para sujetar. De esa forma, el espacio de la discoteca se articulará como un lugar cuyo acceso posibilitará una desaceleración de la protesta homosexual, por cuanto se ha suscitado un punto de encuentro que debiera apaciguar el resto de índices discriminatorios que afectan a tal población. Asimismo, ese espacio habilita una mirada estatal que puede ordenar la disposición de dichos individuos a lo largo y ancho de la ciudad, desde ahora concentrados en puntos distinguibles y fiscalizables.

En ese sentido, he aquí que Ramírez dibujará una cartografía urbana que enseña cuáles son los espacios que se han dispuesto para la celebración de este baile marginal. El poeta, así, ha comprendido que el recorrido urbano que cada sujeto puede realizar por la urbe se halla prediseñado discursivamente, de modo que la colectividad de la que habla sólo festeja la fantasía que le ha sido enseñada:

Míreme el consumo descariñado de mis padres / mire lo que ha hecho la publicidad con nuestras formas de caminar, / con nuestras formas de amar en los parques y en las discos / Mire compañero de luchas pasadas / Cómo me duele a mí también la derrota de mi barricada / plástica y bella, al mismo tiempo [...] Mire la moda, cómo nos inventa canciones homofóbicas / Que mis compañeras de deseo / No entienden y bailan gimiendo (54).

La publicidad y la moda serán los nombres identificados como dispositivos simbólicos encargados de nutrir el inconsciente de esta juventud danzarina, precisamente para con posterioridad, y de modo invisible, levantar las señaléticas que los conduzcan hacia la disco. A la voz poética le interesará, entonces, señalar cómo los cuerpos que bailan, la noche que los cobija y la ciudad que los circunda no son sino todo un simulacro. Así, Ramírez precisará en Relamido, obra coeditada con Gladys González el 2002, una representación de nuestra capital caracterizada como el «Nuevo Santiago» (44), el «Circo-Santiago» (44); todo en su conjunto una simulación impulsada por ese «libre consumo de la ciudad cada vez más violenta» (43), que regula el tránsito de los cuerpos por ella. Si pensamos cómo las discotecas homosexuales fueron ideadas como parte del mercado, Ramírez advertirá que la ciudad toda, y sus habitantes, son el resultado de ese proceso.

De acuerdo con lo anterior, las retóricas nerudiana y queer librarán su batalla sobre el campo escénico de un Santiago nocturno y tangencial, mientras la metáfora de una historia y unos cuerpos plastificados se movilizará ahora hacia su espacio de encuentro: la discoteca. Aquí, la épica queer dirá la sublime falsificación de una cultura emplazada 
por excelencia en la ciudad. En ese sentido, el lugar del baile será el espacio donde el sujeto revisará el estado cultural de la nación, comprendiendo que la realidad, su percepción, ha sido velada por envases y bolsas de plástico, por pantallas y superficies reflectantes:

No hay nadie esta misma noche que me lleve a sus espectáculos de iluminación láser, de sus pantallas gigantes, de sus chicos de acrílico desfilando la marca especial boys.

No hay nadie que pueda venir a cambiarme las cosas o generalizar otra miradita, si ya los tengo a todos bailando como reliquia pop, como pastiche de moda (Ramírez, El baile, 23).

El láser y el acrílico, así como la marca y la reliquia, imaginan una realidad vuelta pastiche, en cuanto su experimentación es vacía y refractaria, y en tanto se extiende sobre una superficie que hacia ninguna parte se socava. La historia aparece cancelada por la intervención del ícono pop como instrumento mítico al que asirse, en tanto al interior de la discoteca, como en el tiempo del mito, «no se vive ya en el tiempo cronológico, sino en el tiempo primordial» (Eliade, 25). De esa manera, Morrisey, Björk o Pulp se articularán como los puntos cardinales que ordenarán y explicarán al sujeto su universo: «El baile nacional de los niños (DISCO 2000)» (Ramírez, El baile, 37) será el himno que unificará la construcción de una identificación subjetiva y colectiva entre los sujetos, al mismo tiempo que los desmarca de su actuación como individuos de una nación, los desancla de su participación política, ciudadana.

Así, la experiencia del baile se realizará rito capaz de devolver a los sujetos una imagen de lo divino y lo cósmico ${ }^{12}$. De ese modo, un personaje como Madonna se convertirá en «La diva pop que proclama su amor capitalista por la plastificación musical, el ritmo santificado por la Isla Bonita que los chicos violetas dibujan en su anatomía frutilla. El emblema divino que es venerado desde la pasión extraviada» (Ramírez, «Relamido II», 44). Los sujetos, al perseguir e imitar la coreografía, hallan una identificación allí donde se desvanece la historia, al tiempo que aparece el goce. Aquí se fabricará la fantasía del inconsciente introyectado desde la cultura: se desea el espectáculo, se desea el plástico, pues las nuevas tecnologías han enseñado que detrás de la pantalla se halla la completitud. Ingresar a la disco, entonces, implicará fugarse de Chile: «Ese simulacro lejano a toda la fritanga que afuera sobre la Alameda espera a las micros criollitas para irnos y volver, para ver cómo tanta plástica realidad modela en medio del Teatro Carrera, el último gritito generacional que le queda a la diferencia bailable» (El baile, 22; el énfasis pertenece al texto). De esa forma, al interior de la disco se desencadenará un desplazamiento identitario que difuminará las coordenadas espacio-temporales que sujetan a los individuos fuera de ella; adoptando la forma de una compensación fantasmática, al interior de la disco cada individuo accederá a la satisfacción de un deseo imposibilitado al exterior de ella.

Por su parte, también el signo amoroso entre los sujetos aparecerá metaforizado desde una marginalidad simulada. Esos individuos «se masturban en las tardes de ocio ciber express» (Ramírez, El baile, 64), se reconcilian «debajo del puente» (71) y «Mientras se duermen las madres y se enfilan las vigilancias municipales / En los cerros / allá arriba /

12 De acuerdo con Mircea Eliade, «el mito siempre se refiere a una «creación', cuenta cómo algo ha llegado a la existencia o cómo un comportamiento, una institución, una manera de trabajar, se han fundado: es ésta la razón de que los mitos constituyan los paradigmas de todo acto humano significativo» (25). En el caso de la disco, me parece que el baile precisamente actualiza una experiencia del origen, en este caso encapsulada en la pantalla de TV: desde ahí se hizo el mundo. 
bien lejos / los niños suicidas se aman despacito / En la ruleta sexual / clandestina» (76). La cartografía afectiva de ese mundo bailable sigue siendo dicha del mismo modo, en cuanto que las experiencias continúan nocturnas y encubiertas, efectuadas en aquel suplemento de realidad patrocinada por el Estado, donde los indigentes de la ciudad tienen licencia para armar sus camas de cartón.

De esa forma, la imagen predominante para enunciar la relación entre estos cuerpos será la de un comercio ilegal: «Traficando su paso bailable / cuerpecito misógino plástico enseña / girando luces celeste bordadito / su sueño conmigo» (Ramírez, El baile, 15); «Yo sé que me quiere / que me abraza / que me delata/ que me financia» (49). La noción de tráfico, resignificada por la artificialidad y la ficción económica, termina de construir el imaginario de unos cuerpos neoliberales, relacionados a través de una transacción comercial que, sin embargo, para esos sujetos, ha sido instruida como ilegal, al margen de la ley, como si de lavado de dinero amoroso se tratara.

De la misma manera, entonces, Ramírez adoptará la posición del sujeto que transgrede la interdicción: desde ahora figurará como delincuente, criminal: «Me encerrarán 93 días en las piezas de tus fobias / Desafiaré las iras y las culpas» (El baile, 45). A su vez, la voz poética finalizará por medio de una adaptación policial, titulada «Antecedentes del autor», en la que agregará que «Estoy tan arrepentido de ser una loca criminal / Un desadaptado / bailable / Un narcotraficante de ti» (99). La conformación subjetiva del hablante se afiliará a la experiencia marginal de los otros cuerpos que ha representado, y desde ahí enunciará la calidad delictual de su homoerotismo.

No obstante, he aquí que su posicionamiento también se volverá ambivalente. Lo anterior, en cuanto que si bien Ramírez se asume como parte de la colectividad, por ejemplo al afirmar que «En este baile sólo invitamos a los que respetan el rito del abandono» (El baile, 23), también construirá su yo desde la diferencia, precisamente porque sus chicos «no saben leer» (39). De ese modo, se ha generado una distinción que manifiesta la ostensión de un saber particular de la voz poética, que sí ha sido capaz de leer el discurso oficial, que sí ha sido capaz de comprender la voz nerudiana y que sí ha podido fracturarla a través de su interrupción queer. Por tanto, la criminalidad del hablante aparece desdoblada, precisamente en tanto no sólo su cuerpo es clandestino, sino que también su enunciación ha herido la superficie del simulacro urbano, al resolver cómo la plastificación de su deseo ha sido manufacturada por las políticas públicas, concentradas en desencantar a la población de su actividad política, estimulando el consumo en vez de la protesta, la huida en vez del encuentro.

De ese modo, y emergiendo desde esa capital nocturna, desde la pista de baile violeta, el novísimo Diego Ramírez representará el pastiche de un mundo que danza de espaldas a la nación y marginal a la historia. Los chicos de los que habla el poeta no bailan a plena luz del día, en el centro de la ciudad. A ellos les interesa poblar los espacios urbanos limítrofes que, como umbrales espacio-temporales, los fuguen de nuestro país. Precisamente he ahí el Teatro Carrera, o la discoteca Blondie, recreando esta fantasía: el primero, un teatro abandonado; la segunda, un local subterráneo: ambos inmuebles representan el desperdicio y lo tránsfugo, ambos alimentan una imaginación fugitiva. Allí, en el ex aristocrático barrio Concha y Toro, o rodeados de Estación Central, cerca de Meiggs y el barrio Yungay, estos sujetos viven las experiencias reversas de sus estaciones de metro: República o Unión Latinoamericana, nombres utópicos vaciados de sentido, sustituidos por pantallas, plásticos y fantasmas. 
Para finalizar, la degradada fiesta de simulaciones representada por Ramírez, al adquirir conciencia escritural, al ser desdoblada y vuelta significante, será sublimada a través de su retórica queer. Ello, al tiempo que la nación, institucionalizada por el canto nerudiano, se vuelve el baldío, la letra que hay que anular. El pastiche bailable, entonces, imaginará cómo la ciudad toda es ese simulacro, esa fantasía consumista dedicada a borrar lo que los sujetos tienen de ciudadanos. Al fin, el proyecto de Ramírez entenderá que estos chicos tecno efectivamente son los hijos del tirano, o bien, los nietos educados por la Concertación de Partidos por la Democracia de Chile.

\section{REFERENCIAS}

Bajtín, Mijaíl. Problemas de la poética de Dostoievski. Tatiana Bubnova (trad.). México: FCE, 1993. Medio impreso.

Bersani, Leo. Homos. trad. de Horacio Pons. Buenos Aires: Manantial, 1995. Medio impreso.

Eliade, Mircea. Mito y realidad. trad. de Luis Gil. Barcelona: Kairós, 2003. Medio impreso.

Espinosa, Patricia. «La poesía chilena en el periodo 1987-2005». Letras S.5. Escritores y poetas en español. 2006. Sitio Web.

Freud, Sigmund. «Lo ominoso». Obras Completas XVII. José Luis Etcheverry (trad.). Buenos Aires: Amorrortu, 1976. 215-252. Medio impreso.

Guerra, Lucía. "Género y cartografías significantes en los imaginarios urbanos de la novela latinoamericana». Más allá de la ciudad letrada. Ed. Boris Muñoz y Silvia Spitta. Pittsburgh: Universidad de Pittsburgh, 2003. 287-306. Medio impreso.

Hernández, Héctor. «Panorama subjetivísimo de la novisísima poesía chilenísima». Letras S.5. Escritores y poetas en español. 2004. Sitio Web.

Jameson, Fredic. El posmodernismo o la lógica cultural del capitalismo avanzado. trad. de José Luis Pardo Torío. Barcelona: Paidós, 1991. Medio impreso.

Neruda, Pablo. Canto general. Buenos Aires: Seix Barral, 1993. Medio impreso.

Ramírez Gajardo, Diego. El baile de los niños. Santiago de Chile: Ediciones del Temple, 2005. Medio impreso.

. «Relamido II». Relamido (Crónica + Poesía). Santiago de Chile: Balmaceda 1215, 2002. 31-59. Medio impreso.

Richard, Nelly. Márgenes e instituciones: arte en Chile desde 1973. Santiago de Chile: Metales Pesados, 2007. Medio impreso.

Robles, Víctor Hugo. Bandera Hueca. Historia del Movimiento Homosexual en Chile. Santiago de Chile: ARCIS / Cuarto Propio, 2008. Medio impreso.

Ruiz, Felipe. "Bajezas de Machu Pichu». Desencanto personal. Reescritura de Canto General de Pablo Neruda. Santiago de Chile: Cuarto Propio / Balmaceda 1215, 2004. 127-139. Medio impreso.

. «Dulce perversión infantil. Reseña de El baile de los niños de Diego Ramírez». Letras S.5. Escritores y poetas en español. 2006. Sitio Web. Fecha de ingreso: 15 de mayo de 2010. 
. «Poetas en el acto: generación de los novísimos». Tesis de Periodismo. Universidad de Chile, 2008. Medio impreso.

Sepúlveda, Magda. «Poetas del año 2000: En la disco y en la ruina del posChile». Ponencia presentada al Encuentro Internacional Poesía y Diversidades, Universidad de Chile, 2010. Inédito.

Stein, Arlene y Ken Plummer. «I can't even think straight»: ¿Queer» theory and the missing sexual revolution in sociology». Queer Theory / Sociology. Ed. Steven Seidman. Cambridge, Mass: Blackwell, 1996. 129-144. Medio impreso.

Urriola, Malú. "Apellido materno y El baile de los niños de Diego Ramírez Gajardo". Letras S.5. Escritores y poetas en español. 2005. Sitio Web. Fecha de ingreso: 16 de mayo de 2010.

Recepción: Julio 2011

Aceptación: Noviembre 2011 